\title{
Automation possibilities in a low rotation warehouse of a Belgian manufacturing plant. A case study
}

\author{
Anca Mocan ${ }^{1, *}$, and Anca Draghici ${ }^{1}$ \\ ${ }^{1}$ Politehnica University of Timisoara, Faculty of Management in Production and Transportation, \\ 14 Remus Street, 300191 Timisoara, Romania
}

\begin{abstract}
Lack of appropriate warehouse ergonomics is one of the leading causes of worker injuries in industry environments. As management teams are trying to reduce the cost of doing business, they look to worker's health statistics and realize they must improve their way of operating. The paper presents a warehouse analysis done at the request of the management team of a Belgian manufacturing plant. The factory's warehouse was audited with focus on Kanban bin weight, storage rack height and rack width to assess the ergonomic strain it causes on workers. The paper then presents possible automation options in order to find the best fit to reduce ergonomic impact, while also optimizing the total investment cost.
\end{abstract}

\section{Background}

It is well known in the industry that manual material handling is a hazardous activity for a worker's health $[1,2]$, where there is a direct relation between the quantity and intensity of work and the increase in injury rates $[3,4]$. The Supply Chain management team of a manufacturing and assembly factory in Belgium (BTB) approached the authors of the paper with the request to audit the ergonomic weak points of its Kanban warehouses, in regards both to the company's internal guidelines as well as the national work safety legislation. The Kanban infrastructure of the production warehouse was audited over the course of three months, in order to assess its "As-Is" status. After the assessment completed, a series of automation and Industry 4.0 related solutions were analyzed with regards to their capability to improve the ergonomic environment in the warehouse.

The improvement proposals also considered the total financial investment in the hardware and the time invested in training the final system users. All in all, the research lasted 5 months and was presented officially to the company's management team in December 2018. Within the industry the company operates in, ergonomic audits are not usually applied in the production area itself, but rather in the operational management of the of the products after they have left the assembling plant [5].

The context of ergonomics in the warehouse is often presented by its regulatory health and safety aspect, while not enough light has been shed on the competitive advantage

\footnotetext{
*Corresponding author: ancamocan2003@yahoo.com
} 
opportunities that its applications can lead to. In most current business articles [6-9] ergonomics principles are presented at a base level, often in a "Tips and tricks" or "practical ergonomics" format, oversimplifying the information and its implementation. Based on the research the company pledged to make certain changes to the internal warehouse organization, but the research team did not stay on to observe what changes were made and if the recommendations of the research were being followed.

\section{Analysis}

\subsection{Measurement of the warehouse Kanban racks}

As it is not the standard understood definition, internal Kanban in this analysis is defined as Kanban activities that must be done internally within the factory (for example, filling the bins, scanning the bins, management of internal deliveries). External Kanban refers to activities fully outsourced to the supplier in which the factory does not activate at all. The analysis was done on the internal Kanban racks and procedures, with the aim to understand whether the current processes respect ergonomic norms and regulations.

There is a grouping of racks in each location. One rack per assembly station was sampled and all full bins in that rack were weighed. Full bin was defined as bins where no parts were removed. As the running system was Kanban, where (minimum) two bins existed per rack for the same article number, the second (filled) bin was measured as it was maximally full. The measurement of the weight was done with a handheld Samsonite Digital Luggage Scale Torch Black (Figure 1) with a maximum analyzable weight of $40 \mathrm{~kg}$ and a sensitivity of $10 \mathrm{~g}$. The bins were hooked to the scale and left to hang until the digital scale confirmed the final weight via a sound signal.

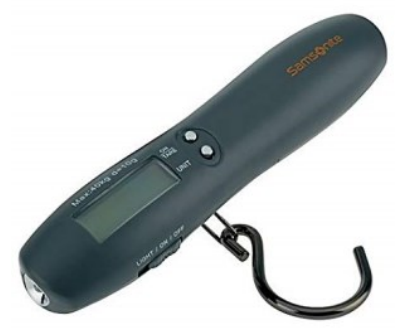

Fig. 1. Samsonite Digital Luggage Scale Torch Black.

The weight of the filled bins measured between $270 \mathrm{~g}$ and $28.870 \mathrm{~g}$ overall, with the weight of the bin itself included in the measurement. The weight per each rack level along with the ergonomically recommended maximum weight per related height is presented in Table 1.

Even though only one rack was chosen for measurement per assembly station, in one case a rack that was not selected for the random check was noticed to have what seemed to be a heavy bin on the uppermost level. Upon trying to measure it, the bin proved very difficult to lift by the observer and caused the scale to make cracking noises as it lifted the items. The full weight was not measurable by the scale, but it was ultimately not taken into consideration in the analysis as it did not satisfy the self-imposed selection procedure. The Belgian law doesn't specify the maximum legally allowed weight specifying only that construction companies cannot ask their personnel to lift more than $25 \mathrm{~kg}$ [5]. The European theoretical limit is $25 \mathrm{~kg}$ [6]. The theoretical limit implies that the conditions for lifting are ideal (the weight is kept close to the body, at hip height, with a good grip and without the turning of the back). If these conditions are not met the weight capable of being lifted decreases. 
Table 1. Range of weight and height per rack level

\begin{tabular}{|c|c|c|c|c|c|c|c|c|}
\hline \multirow[t]{2}{*}{$\begin{array}{l}\text { Rack } \\
\text { level }\end{array}$} & \multirow[t]{2}{*}{$\underset{[g]}{\operatorname{Max}}$} & \multirow[t]{2}{*}{$\begin{array}{l}\text { Min } \\
{[g]}\end{array}$} & \multirow[t]{2}{*}{$\begin{array}{l}\text { Average } \\
\quad[g]\end{array}$} & \multicolumn{3}{|c|}{$\begin{array}{l}\text { Rack height average } \\
\qquad[\mathrm{mm}]\end{array}$} & \multicolumn{2}{|c|}{$\begin{array}{l}\text { Ergonomically theoretically } \\
\text { recommended maximum [g] }\end{array}$} \\
\hline & & & & $\begin{array}{l}\text { Rack } \\
\text { type } 1\end{array}$ & $\begin{array}{l}\text { Rack } \\
\text { type } 2\end{array}$ & $\begin{array}{l}\text { Rack } \\
\text { type } 3\end{array}$ & Men & Women \\
\hline ALL & 28870 & 270 & 6066,73 & & & & \multicolumn{2}{|c|}{25000} \\
\hline 1 & 22050 & 740 & 5354,46 & 190 & 130 & 120 & 10000 & 7000 \\
\hline 2 & 7040 & 570 & 1998 & 500 & 400 & 430 & 20000 & 13000 \\
\hline 3 & 18610 & 950 & 7639,33 & 800 & 680 & 790 & 25000 & 16000 \\
\hline 4 & 15100 & 500 & 3464,53 & 1110 & 950 & 1410 & 20000 & 13000 \\
\hline 5 & 28870 & 270 & 7304 & 1400 & 1220 & 1530 & 10000 & 7000 \\
\hline 6 & 7530 & 500 & 3393,33 & 1700 & 1500 & 1650 & 10000 & 7000 \\
\hline
\end{tabular}

The ISO 11228-1 norm related to the manual lifting of weights mentions $25 \mathrm{~kg}$ as the maximum weight capable of being lifted by the overall work population but depending on the count of manipulations per minute this value decreases. With a frequency of five times per minute maximum weight becomes $20 \mathrm{~kg}$ [7]. The internal BTB specifications limits the maximum amount of weight to be lifted to $20 \mathrm{~kg}$ in total, the internal guidelines not considering any height differentiation, which, as Table 2 shows, is clearly significant.

Table 2. Average Belgian height [mm]

\begin{tabular}{|c|c|c|c|}
\hline Height & P5 & Average & P95 \\
\hline Shoulder height & 1259 & 1394 & 1529 \\
\hline Elbow height & 992 & 1094 & 1196 \\
\hline Knee height & 403 & 446 & 489 \\
\hline Buttocks-Knee Length & 554 & 607 & 660 \\
\hline
\end{tabular}

A first point of attention is related to the fact that there is no separation in the internal factory norm between the maximum liftable weight by men and women. Regardless of this point, this maximum defined weight of $20 \mathrm{~kg}$ has been anyway surpassed by the two different bins found in the racks. In addition to this, as mentioned above and visualized in Figure 2. the maximum liftable weight varies depending on the distance the weight is kept from the body and the height that the weight is placed on. 


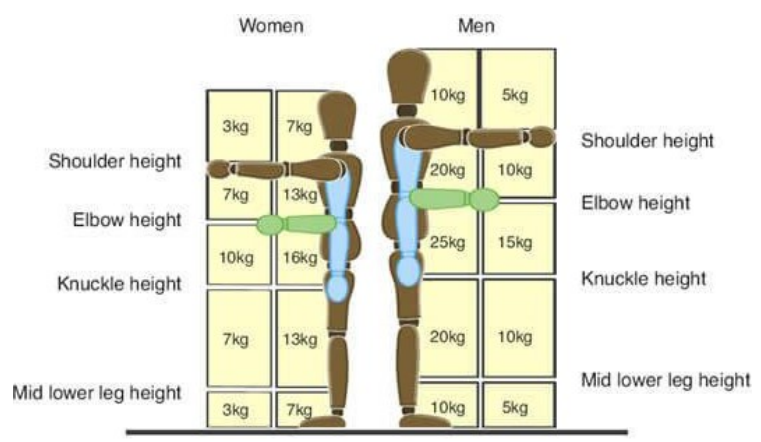

Fig. 2. Lifting and lowering guidelines provided in guidance material [8].

Given this information, the situation in the racks are not only stacked properly for women workers in $17 \%$ of the cases and for men in $70 \%$ of the cases. There is also a wide and lower skewed distribution of the weight per rack, the smallest weight being 270 grams.

A first point that must be immediately improved is the maximum weight policy. Firstly, the national legislation needs to be obeyed, therefore a direct and immediate reduction of the lot size of bins which exceed the legal limit should be done. The bins found to already have overstepped the legal limit need to be removed from the racks and split into smaller lots.

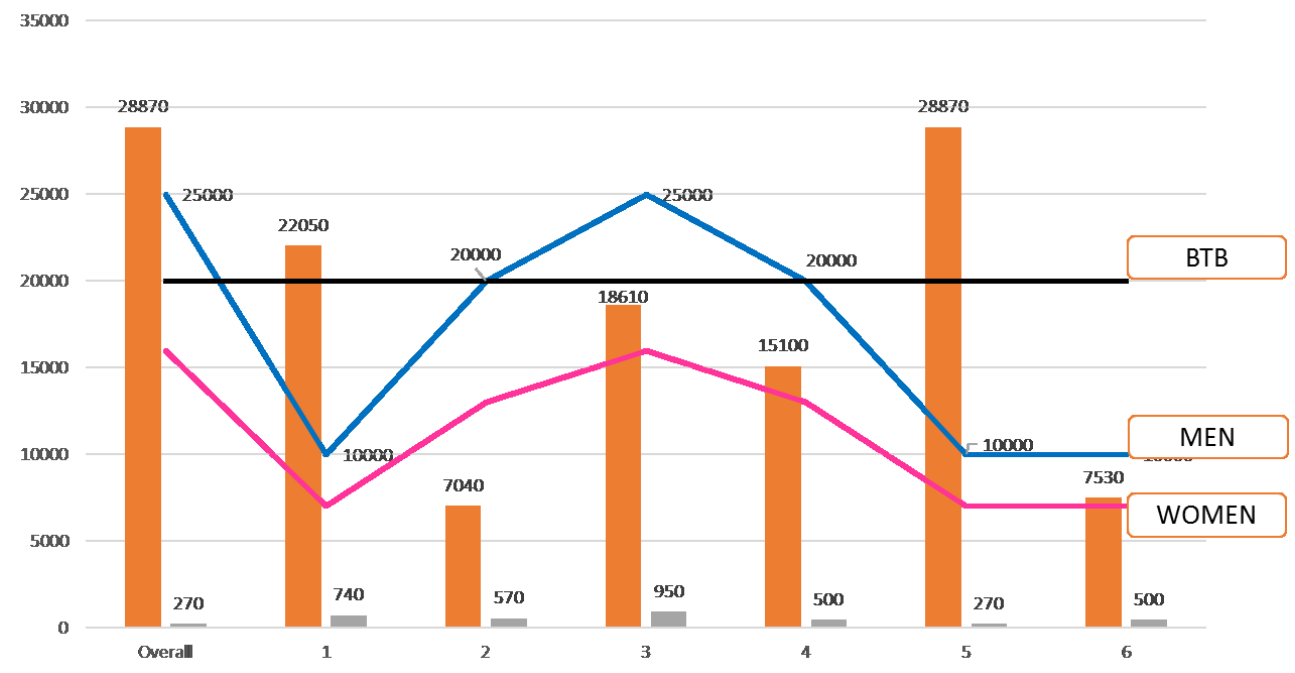

Fig. 3. Weight of the racks and legal limits.

As with the measurements of the weight of the bins, the measurements regarding the width between the racks was done on the internal Kanban racks. The reasons the width between the racks was chosen for analysis is because the proper handling of bins implies crouching in front of the racks in order to correctly remove or replace them. This cannot be done if the space between the racks is insufficient, therefore an analysis was needed to understand what the "as is" situation holds.

One random gangway was chosen for each assembly station where a gangway existed. The distance was measured between the two most outward points of the rack (not the rack ledge itself, but the outward bending sticker ledge) with a standard issue tape measure. The measurements can be seen in Table 3 . 
Table 3. Width of inter-rack gangways and dimensions of Kanban bins [(mm)]

\begin{tabular}{|c|c|}
\hline Measure & Width \\
\hline $\mathbf{1}$ & 920 \\
\hline $\mathbf{2}$ & 820 \\
\hline $\mathbf{3}$ & 860 \\
\hline $\mathbf{4}$ & 910 \\
\hline $\mathbf{5}$ & 1040 \\
\hline $\mathbf{6}$ & 830 \\
\hline $\mathbf{7}$ & 1010 \\
\hline
\end{tabular}

\begin{tabular}{|c|c|c|c|c|c|}
\hline & Height & Width & Length & $\begin{array}{c}\text { Knee } \\
\text { width }\end{array}$ & $\begin{array}{c}\text { Minimum } \\
\text { width }\end{array}$ \\
\hline S & 130 & 150 & 245 & 700 & 850 \\
\hline M & 200 & 220 & 340 & 700 & 920 \\
\hline L & 200 & 320 & 500 & 700 & 1020 \\
\hline
\end{tabular}

The first observation to come out of the analysis was that there were no procedures or guidelines specifying the width of space necessary between two racks for proper kneeling/crouching capabilities. As presented in Figure 4, the distance necessary for crouching or kneeling is, on average, $700 \mathrm{~mm}$.

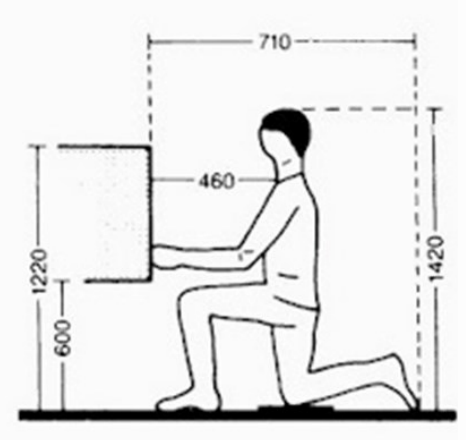

(18) Kneeling

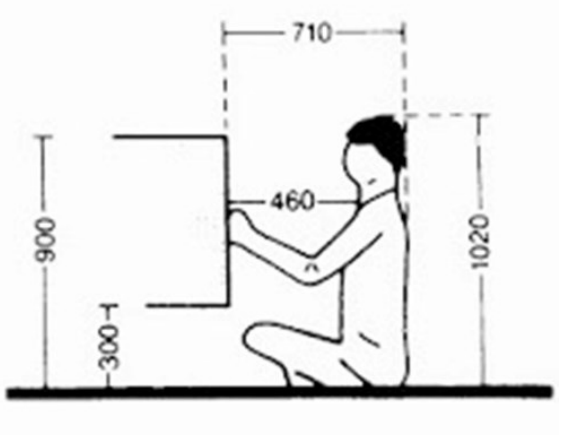

(20) Squatting

Fig. 4. Distance needed for kneeling or squatting [9].

If only this distance is to be taken into consideration, the width of the racks proves to be satisfactory. However, the main purpose of the logistics worker is to stack the filled bins on the rack and remove the empty ones. Therefore, one must take into consideration the length of the bins being placed. This means that the minimum distance needed to place/remove something from the rack is the usual kneeling distance plus the length of the largest bin that is set in the rack. The length of the biggest bin is $500 \mathrm{~mm}$. As there is no rack in which the large size bin is systematically forbidden to be placed the minimum width between two racks must be $1020 \mathrm{~mm}$.

If the minimum width is thusly measured the racks are therefore shown to be inadequate more than $85 \%$ of the time. This implies that none of the workers can follow standard ergonomic recommendations when filling in or removing the bins. They must approach the bin from the side, increasing the chance of torsional injuries of the lumbar spine that occur with load application accompanied by axial rotation. In these, damage occurs in both the annulus of the disc and the neural arch possibly causing traumatic arthritis and enabling the development of torsional deformities and subsequent neural compromise.

Furthermore, the labelling of the racks proved to be a difficult to follow system. Bins were grouped in a specific assembly station based on engineering designated needs. The article numbers related to the pieces stored in the bins were stacked in racks based on the last digit. For example, rack A, side A contained all articles ending with a "1", rack A side B contained all articles ending with a "2", etc. While this did ensure that workers would be 
looking in the same general area for a bin to pick, the exact location would not be easily retrievable. Because of this, workers would lose time trying to find the correct item to pick. As there was no designated line picker who could, eventually, learn to navigate the racks sooner, most of the workers would lose their way quickly, or pick a wrong article. This led to small, but consistent daily delays and mistakes in the process.

\subsection{Improvement possibilities}

Continuing previous research into the ergonomic efficiency of warehouse equipment [10] the following paragraphs will present an analysis of the existing wearable computers that has been made based on three perspectives or criteria namely the total investment amount, ergonomic efficiency and ease of use Now that each topic's background has be presented, an analysis will be made as to whether the issue could be solved with at least one type of solution, be that classical or Industry 4.0. This solution will be graded based on three areas of importance, namely investment amount, ergonomic efficiency and ease of use. These aspects will be graded on a scale of 1 to 5 with 1 being least desirable and 5 being most desirable, based on which would maximize the efficiency equation (1) (the notations used are: $\mathrm{E}$ is the overall efficiency; I - investment; Ee - Ergonomic efficiency; Te - Training effort; $\mathrm{p} 1, \mathrm{p} 2, \mathrm{p} 3$ - weight given to each factor).

$$
E=\frac{I^{*} p 1+E e^{*} p 2+T e^{*} p 3}{p 1+p 2+p 3}
$$

The example grading explanation (Table 4) shows that the best possible grade that an equipment can get is 15 if all the weights in the formula (1) are equal to 1 . Furthermore, the investment refers exclusively to the financial investment for purchasing the equipment and not subsequent training costs. The ergonomic efficiency refers to the capacity of the equipment to reduce strain on the human body that would otherwise be caused by the manual manipulation that the equipment is replacing. The ease of use refers to the amount of time the average worker needs to spend in training in order to be able to use the equipment in the correct way, as specified by its producer.

Table 4. Grading explanation.

\begin{tabular}{|c|c|c|c|}
\hline Grade & Investment & Ergonomic efficiency & Training effort \\
\hline 1 & $€ 5.000-€ 10.000$ & $\begin{array}{c}\text { Minimal manipulation strain } \\
\text { reduction }\end{array}$ & 1 -week training \\
\hline 2 & $€ 1.000-€ 5.000$ & Average manipulation strain & $1-3$ days training \\
\hline 3 & $€ 500-€ 1.000$ & reduction & 1 -day training \\
\hline 4 & $€ 300-€ 500$ & $\begin{array}{c}\text { Complete manipulation strain } \\
\text { reduction }\end{array}$ & $1 / 2$-day training \\
\hline 5 & $<€ 300$ & r & ray training \\
\hline
\end{tabular}

Due to the current financial situation of BTB's Belgium entity, the factors will be weighed to increase the importance of the financial investment by a factor of 3, and the training effort by a factor of 2 . This decision was taken due to the nature of the business. Cash flow problems often arise in the working reality of the company due to the nature of the product they make and because of this a quick return on investment and freeing up personnel from training as soon as possible are more incentivized than ergonomic efficiency. Furthermore, the investment values and training effort mentioned in Table 4 also reflect the current financial 
reality of the company. The investment bracket and total cost will be calculated relative to BTB's warehouse needs.

\subsubsection{Large weights to be lifted from uncomfortable heights}

A possible technical solution for this issue is the vertical parts carousel. The solution considers a series of bins or trays linked together to create a continuous chain, mounted on an elongated vertical oval track. It is a type of automated storage and retrieval system (ASRS) that revolves until it brings the appropriate bin, tray or other carrier to the operator. Once the carousel has stopped, its operator can pick the required product from its shelf, thus requiring no movements from the operator's side. This can help reduce the ergonomic strain caused by having to lift items from heights. However, the system is most efficient when placed in an area with vertical accessibility, as standard options have a minimum height of 3 meters. While it's possible to find that height in the warehousing area, the production line where the analyzed shelves are placed has a limited available height of 2 meters. If the solution were to be chosen, the warehousing reality would have to be rethought.

The part-to-picker method uses three organizational elements: a storage area, a picking area, and a material handling system. The automation level of the material handling system may vary, along with the technical solution, but the result of the system is that the products are moved from the storage area and delivered to the picking areas. The picking operator then collects the products after they're delivered to their area and continues to fulfil their jobs. This type of setup requires heavy automation and is usually suited for large warehousing facilities with high SKU picking needs. It can also cause wasted labor because picking operators may find themselves waiting for items to be delivered to their picking location. If the solution were to be chosen a compounded storage area for the manufacturing line would have to be decided in order to keep the financial investment to a minimum.

\subsubsection{Small manoeuvring spaces for workers between racks}

Gliding pallet racks, as visualized in Figure 4, are a type of high-density moving pallet shelf storage systems that save space in warehouses by eliminating static forklift aisles and transforming them into a dynamic, mobile storage. This type of tool allows better space usage by facilitating gliding the storage areas to suit ergonomic picking needs better. The movement can be further automated by integrating a package location system that automatically moves the racks to reveal the correct location upon a worker's approach. The automated version might be too big of an investment for the part picking along the production line, but the solution that involves manually moving the racks could be easily implemented and useful. As the analysis investigates automated solutions however, the automated solution will be the one costed in the efficiency table.

Autonomous robot carriers (ARC), as visualized in Figure 5, are robots that autonomously pick up and drop off carts to any location within facilities with material handling needs. Multiple sensors guide the robot between locations and safety sensors allow it to work alongside people, forklifts, and other material handling equipment. With an average speed of up to 1.5 meters per second, the robot can bring the parcels directly to the end user. This solution could provide to be an opportunity to completely remove the storage areas along the production line and have the line feeding occur directly from the warehouse into production, thus reducing the work tasks on the production line and consolidating all of them to a warehouse line feeder. 


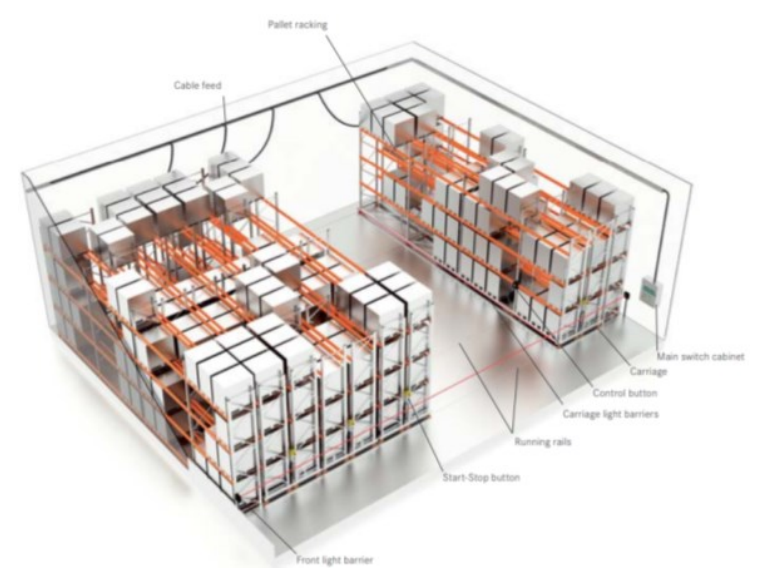

Fig. 4. STILL sliding rack technical solution.

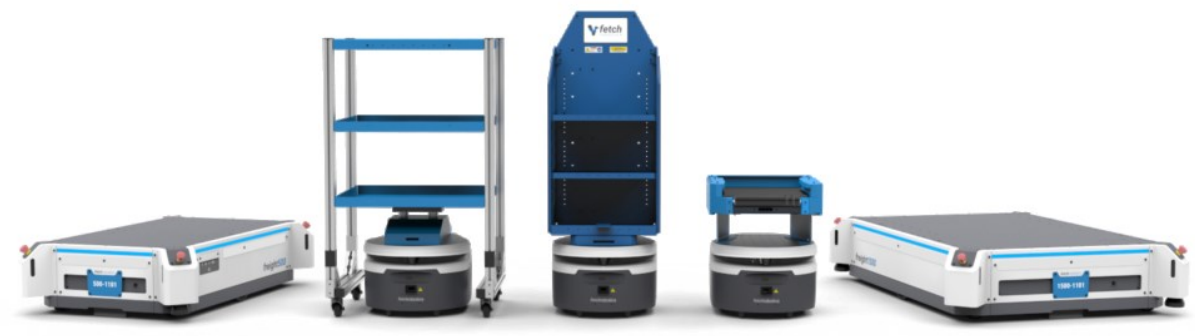

Fig. 5. Cart and pallet transportation solutions (solutions from Fetch robotics).

\subsubsection{Hard to read/ unorganized labels}

Pick by light, as visualized in Figure 6, improves order fulfilment performance by reducing the time spent walking between items required by an order, and removing the errors associated with reading paper pick lists. The solution reduces errors by having the location of the manually scanned picking list items light up to guide the picker. This solution is fast to implement and required minimal training, while reducing typical picking errors and eliminating the need for labels altogether.

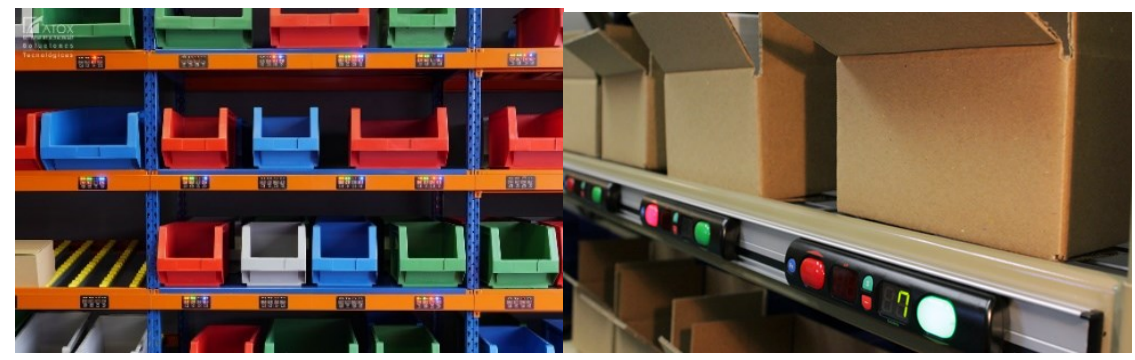

Fig. 6. Pick to light system solutions (solutions from Atoxgrupe; Lightning Pick). 
Pick by voice: Are a hand free, eyes free operation where workers head instructions via a headset and don't have to look down at a part picking list. The voice terminal interacts in real time with the warehouse management system and guides the operator with increased accuracy to the picking point. Companies that provide this service have presented anywhere from $10 \%$ to $60 \%$ picking improvement as a result.

In the case of pick-by-light or pick-by-voice options, from a technological standpoint there is no definitive answer as to which is better. It is highly dependent on the type of work being done in the warehouse and the overall business requirements. Pick-to-light also makes sense in warehouses or distribution centres that have lower SKU counts, primarily because a smaller environment helps keep costs in check as the price of pick-to-light is directly tied to the number of SKUs because lights must be physically installed on every rack and pick location [11].

The most advanced version of semi-automated picking leverages the usage of augmented reality to reduce picking errors by overlaying graphical images over worker's line of vision and enhancing objects with additional information in real time. As providers of such solutions have mentioned, this solution also offers the possibility to train employees and to enhance automated warehouse planning [12,13].

The technology is easily scalable and allows quick picking of items with almost no chance of mistake and with no requirements for warehouse relocation or current setup changes, as visualized in Figure 7.

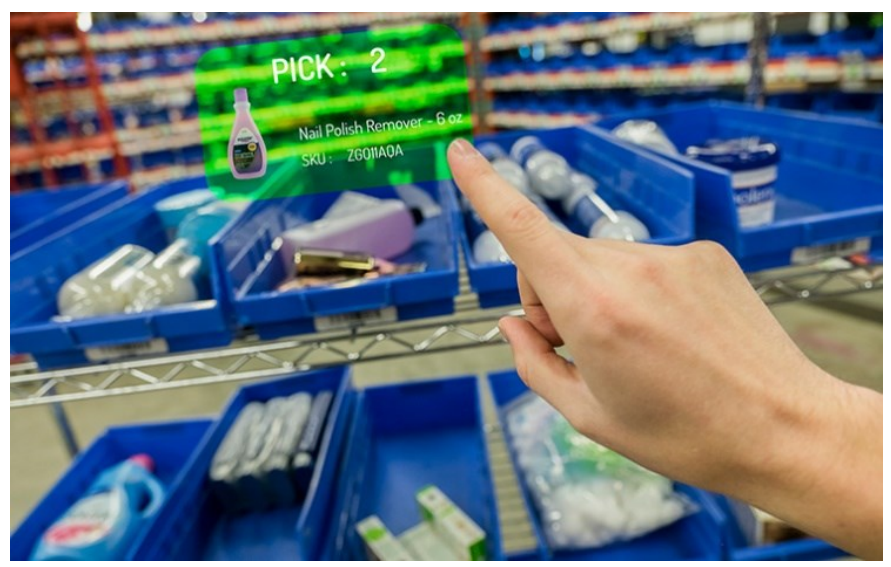

Fig. 7. Bastian solutions AR picking technology.

As with all technologies presented so far there is a stark trade-off between implementing the solution by rack or by picker. Given the current setup of the production line adjacent warehousing area (many small groups of independent warehousing spaces, with large distances in between), the balance would tip towards implementing solutions by picker if the setup is not changed. If the setup is changed and the storage facilities are removed from the production line, then the recommendation would be to automate the racking. As further detailed in Table 5, the advantages of each system in terms of technical capabilities for a series of pre-determined company important factors.

It can be clearly noticed that any improvement brought to the warehouse will bring significant improvement versus the process of manual handling, but while the technical capabilities to improve warehouse ergonomics exist, the financial aspect shouldn't be ignored, especially given the non-optimal financial situation in which BTB currently finds itself. 
Table 5. Technological capabilities.

\begin{tabular}{|c|c|c|c|c|c|c|c|}
\hline & $\begin{array}{c}\text { Autonomous } \\
\text { robots }\end{array}$ & $\begin{array}{c}\text { Vertical } \\
\text { parts } \\
\text { carousel }\end{array}$ & $\begin{array}{l}\text { Part } \\
\text { to } \\
\text { picker }\end{array}$ & $\begin{array}{c}\text { Pick- } \\
\text { by- } \\
\text { Vision }\end{array}$ & $\begin{array}{l}\text { Pick- } \\
\text { by- } \\
\text { Voice }\end{array}$ & $\begin{array}{l}\text { Pick- } \\
\text { by- } \\
\text { Light }\end{array}$ & $\begin{array}{l}\text { Manual } \\
\text { picking }\end{array}$ \\
\hline $\begin{array}{l}\text { Flexible to } \\
\text { use and } \\
\text { expand }\end{array}$ & $\checkmark$ & $\checkmark$ & $\checkmark$ & $\checkmark$ & $\checkmark$ & $\mathrm{X}$ & $\checkmark$ \\
\hline $\begin{array}{l}\text { Location- } \\
\text { independent } \\
\text { use }\end{array}$ & $\checkmark$ & $\mathrm{X}$ & $\mathrm{X}$ & $\checkmark$ & $\checkmark$ & $\mathrm{X}$ & $\checkmark$ \\
\hline $\begin{array}{c}\text { Location } \\
\text { determination }\end{array}$ & $\checkmark$ & $\checkmark$ & $\mathrm{X}$ & $\checkmark$ & $\checkmark$ & $\mathrm{X}$ & $\mathrm{X}$ \\
\hline Handsfree & - & - & - & $\checkmark$ & $\checkmark$ & $\checkmark$ & $\mathrm{X}$ \\
\hline $\begin{array}{l}\text { Strict visual } \\
\text { and mobile } \\
\text { process } \\
\text { guidance }\end{array}$ & $\checkmark$ & $\mathrm{X}$ & $\mathrm{X}$ & $\checkmark$ & $\mathrm{X}$ & $\mathrm{X}$ & $\mathrm{X}$ \\
\hline $\begin{array}{c}\text { Real-time } \\
\text { verification }\end{array}$ & $\mathrm{X}$ & $\mathrm{X}$ & $\checkmark$ & $\checkmark$ & $\mathrm{X}$ & $\mathrm{X}$ & $\mathrm{X}$ \\
\hline Zero fatigue & $\checkmark$ & $\checkmark$ & $\checkmark$ & $\checkmark$ & $\mathrm{X}$ & $\checkmark$ & $X$ \\
\hline $\begin{array}{c}\text { Error rate } \\
\text { virtually zero }\end{array}$ & $\checkmark$ & $\mathrm{X}$ & $\checkmark$ & $\checkmark$ & $\mathrm{X}$ & $\mathrm{X}$ & $\mathrm{X}$ \\
\hline $\begin{array}{l}\text { Integrated } \\
\text { barcode } \\
\text { scanner }\end{array}$ & $\checkmark$ & $\checkmark$ & $\checkmark$ & $\checkmark$ & $\mathrm{X}$ & $\mathrm{X}$ & $\checkmark$ \\
\hline $\begin{array}{l}\text { Intuitive } \\
\text { operation }\end{array}$ & $\checkmark$ & $\mathrm{X}$ & $\checkmark$ & $\checkmark$ & $\mathrm{X}$ & $\checkmark$ & $\mathrm{X}$ \\
\hline $\begin{array}{c}\text { Seamless } \\
\text { integration }\end{array}$ & $\checkmark$ & $\checkmark$ & $\checkmark$ & $\checkmark$ & $\checkmark$ & $\mathrm{X}$ & $\checkmark$ \\
\hline $\begin{array}{l}\text { Usable in all } \\
\text { areas of order } \\
\text { picking }\end{array}$ & $\checkmark$ & $\mathrm{X}$ & $\checkmark$ & $\checkmark$ & $\mathrm{X}$ & $\mathrm{X}$ & $\checkmark$ \\
\hline $\begin{array}{c}\text { Serial } \\
\text { number } \\
\text { scanning }\end{array}$ & $\checkmark$ & $\checkmark$ & $\checkmark$ & $\checkmark$ & $\mathrm{X}$ & $\mathrm{X}$ & $\mathrm{X}$ \\
\hline $\begin{array}{c}\text { Automatic } \\
\text { transport jobs }\end{array}$ & $\checkmark$ & $\mathrm{X}$ & $\checkmark$ & $\checkmark$ & $\mathrm{X}$ & $\mathrm{X}$ & $\mathrm{X}$ \\
\hline $\begin{array}{l}\text { Permanent } \\
\text { inventory }\end{array}$ & $\mathrm{X}$ & $\mathrm{X}$ & $\checkmark$ & $\checkmark$ & $\checkmark$ & $\mathrm{X}$ & $\mathrm{X}$ \\
\hline
\end{tabular}

In order to take this into consideration, Table 6 gathers the tools so far presented and ranks them based on their overall ergonomic efficiency, training effort and investment impact, based on the prices specified by their respective producers. The highest grade that a technology was thus shown to have was 22 points, for the pick by light system. The lowest points were achieved by the gliding pallet racks solution and the part to picker solutions.

The explanation for this is the small size of the warehouse and the relatively low volume of goods being picked daily. There is no incentive to install high automation systems in this situation due to the low return on investment and high collateral cost that, in the end, do not bring a high level of improvement to the daily ergonomic conditions that the workers must face while picking parts. 
Table 6. Overall efficiency-Automation and Industry 4.0.

\begin{tabular}{|c|c|c|c|c|c|}
\hline Topic & Technology & Investment & $\begin{array}{c}\text { Ergonomic } \\
\text { efficiency }\end{array}$ & $\begin{array}{c}\text { Training } \\
\text { effort }\end{array}$ & $\begin{array}{c}\text { Overall } \\
\text { grade }\end{array}$ \\
\hline $\begin{array}{c}\text { Large weights to be } \\
\text { lifted from } \\
\text { uncomfortable } \\
\text { heights }\end{array}$ & $\begin{array}{c}\text { Vertical parts } \\
\text { carousel }\end{array}$ & 1 & 3 & 5 & 16 \\
\hline $\begin{array}{c}\text { Small maneuvering } \\
\text { spaces for workers } \\
\text { between racks }\end{array}$ & $\begin{array}{c}\text { Gliding pallet } \\
\text { racks }\end{array}$ & 1 & 3 & 4 & 14 \\
\hline \multirow{2}{*}{$\begin{array}{c}\text { Hard to read/ } \\
\text { unorganized labels }\end{array}$} & Pick by light & 3 & 3 & 5 & 22 \\
\cline { 2 - 6 } & Pick by voice & 3 & 3 & 4 & 20 \\
\cline { 2 - 6 } & Pick by sight & 2 & 3 & 5 & 19 \\
\hline
\end{tabular}

\section{Conclusion}

While the technologies presented in the paper can improve the ergonomics standing of the warehouse, industry 4.0 tools do not provide a fix all solution that many would hope it would. The main draw of smart devices (or consolidated smart warehouses) is that they offer process automation and interconnectivity. Smart warehouses work to eliminate the use of manual labor and input wherever possible, thus reducing costs and manpower needs. The concept of smart devices is that they open the possibility for more data mining and process optimization [14].

But process automation cannot be applied without stability in the already existent processes. The additional investment in smart technology does not bring an equal improvement in business activities, if those activities were not stable in the first place. Because of this, merely using smart devices to gather more data while not knowing how to use that data to improve the process and train the people leads to suboptimal results. As noticed during the factory audit, the company did not lack in formal process flows and training, but it did lack in employee understanding of the issues, informed managerial guidance and risk response structure. The constant firefighting responses of the company did not allow for stable processes and countered the continuous improvement mentality implemented just a few years earlier.

While the presently done analysis and improvement points recommended are valid in the context of the study, the results from the suggested improvements would be punctual to the BTB factory entity. Because of this, a general approach to ergonomic problem solving needs to be developed in order to open access to ergonomics problem solving outside of the studied case.

In order to be able to improve ergonomics, managers need to easily grasp what their current ergonomic state is, what areas to focus their effort on improving and how to track the improvement process as it goes along.

\section{References}

1. J.D.G. Troup, J.C. Davis, D.P. Manning, J. Occup. Accid., 10, 107-119 (1988)

2. E.R. Vieira, S. Kumar, S. Working postures: A literature review. J. Occup. Rehabil., 14(2), 143$159(2004)$

3. L.I. Gardner, D.P. Landsittel, N.A. Nelson, Risk factors for back injury in 31,076 retail merchandise store workers. AJE, 150(8), 825-833 (1999) 
4. J.F. Kraus, K.B. Schaffer, D.L McArthur, C. Peek-Asa, Epidemiology of acute low back injury in employees of a large home improvement retail company. AJE, 146(8), 637-645 (1997)

5. J.R. Wilson, L. Cordiner, S. Nichols, L. Norton, N. Bristol, T. Clarke, S. Roberts, On the right track: systematic implementation of ergonomics in railway network control. Cogn. Technol. Work, 3(4), 238-253 (2001)

6. B.F. Ware, J.E. Fernandez, Warehouse Ergonomics/Tips and Techniques to Decrease Injury Risk (2014).

7. S. Stone, Ergonomic Safety Tips for the Warehouse (2015).

8. B. Knill, Practical Ergonomics for Plant People (2002).

9. S. Stone, Oversimplification: Four Approaches to Guarantee Limited Safety Improvement (2017).

10. Codex - Boek VIII - Titel 3 - Manueel hanteren van lasten.

11. European Committee for Standardization. EN 1005-2: Safety of machinery-Human physical performance. Part 2: Manual handling of machinery and component parts of machinery (2003)

12. A.D.J. Pinder, M.G Boocock, Prediction of maximum acceptable weight of lift from the frequency of lift. Int J Ind Ergon, 44(2), 225-237 (2014)

13. Manual handling at work (2012).

14. E. Neufert, P. Neufert, J. Kister, Architects' data, John Wiley \& Sons (2012).

15. A. Mocan, A. Draghici, M. Mocan, A way of gaining competitive advantage through ergonomics improvements in warehouse logistics. Res. \& Sci. Today, 13, 7 (2017)

16. B. Stackpole, Take Your Pick (2013).

17. H. Glockner, K. Jannek, J. Mahn, B. Theis, Augmented reality in logistics. Changing the way we see logistics - a DHL perspective (2014).

18. A. Taliaferro, G.A. Guenette, A. Agarwal, M. Pochon, Industry 4.0 and distribution centers Transforming distribution operations through innovation (2016).

19. Warehouse/DC News, Five "Must-Have" Attributes of a Smart Warehouse. 